\title{
Antibacterial and Antioxidant Activities of ZnO Nanoparticles Synthesized Using Extracts of Allium sativum, Rosmarinus officinalis and Ocimum basilicum
}

\author{
Manuela Stan $^{1} \cdot$ Adriana Popa $^{1} \cdot$ Dana Toloman $^{1} \cdot$ Teofil-Danut Silipas $^{1} \cdot$ Dan Cristian Vodnar ${ }^{2}$
}

Received: 12 October 2015/Revised: 26 November 2015/Published online: 19 February 2016

(C) The Chinese Society for Metals and Springer-Verlag Berlin Heidelberg 2016

\begin{abstract}
ZnO}$ nanoparticles (ZnO NPs) were synthesized by chemical method (coprecipitation) and biological method using aqueous extracts of garlic (Allium sativum), rosemary (Rosmarinus officinalis) and basil (Ocimum basilicum). The influence of plant extract on the antibacterial and antioxidant activities of green synthesized nanoparticles was investigated. The X-ray diffraction studies reveal that all $\mathrm{ZnO}$ samples have hexagonal wurtzite structure. The particle size of $\mathrm{ZnO} \mathrm{NPs}$ estimated by transmission electron microscopy analysis (between 14 and $27 \mathrm{~nm}$ ) varies depending on the synthesis method of nanoparticles and the type of extracts from the plants used. The functional groups involved in the biosynthetic procedure were evidenced by Fourier transform infrared spectroscopy. The presence of $\mathrm{Mn}^{2+}$ ions, $\mathrm{Zn}$ vacancy complexes and oxygen vacancies in $\mathrm{ZnO}$ samples was highlighted by electron paramagnetic resonance spectroscopy. The green synthesized ZnO NPs have shown a good bactericidal activity against Staphylococcus aureus, Bacillus subtilis, Listeria monocytogenes, Escherichia coli, Salmonella typhimurium and Pseudomonas aeruginosa bacterial strains. ZnO NPs synthesized using extracts of the selected plant species have been found to exhibit more enhanced antibacterial and antioxidant activities as compared to chemical $\mathrm{ZnO}$ NPs.
\end{abstract}

KEY WORDS: Zinc oxide nanoparticles; Antioxidant activity; Antibacterial activity; Green synthesis; Plant extracts

\section{Introduction}

Microbial contamination is a serious issue in healthcare and food industry so that the development of antimicrobial agents and surface coatings has been attracted increasing attention in recent years [1]. The use of nanoparticles can

Available online at http://link.springer.com/journal/40195

Manuela Stan

manuela.stan@itim-cj.ro

1 National Institute for Research and Development of Isotopic and Molecular Technologies, 67-103 Donat, 400293 Cluj-Napoca, Romania

2 Department of Food Science and Technology, University of Agricultural Sciences and Veterinary Medicine, 3-5 Manastur Street, 400372 Cluj-Napoca, Romania be considered as an alternate, eco-friendly and cost-effective management strategy for the control of pathogenic microbes $[2,3]$.

Of the inorganic materials, metal oxides such as $\mathrm{CaO}$, $\mathrm{MgO}, \mathrm{TiO}_{2}$ and $\mathrm{ZnO}$ have been intensively studied and reported to display enhanced antibacterial activity. Among the various known semiconductors, $\mathrm{ZnO}$ has several advantages: non-toxic, self-cleansing, compatible with skin, and marked antibacterial activity in neutral region $(\mathrm{pH} 7)[4,5]$, etc. Besides these properties, $\mathrm{ZnO}$ has vast applications in various areas such as optical, piezoelectric, magnetic, and gas sensing, and is used more frequently in wastewater treatment, as fungicide [6], and so on. $\mathrm{ZnO}$ nanoparticles ( $\mathrm{ZnO}$ NPs) have also been reported to have antioxidant properties [7]. The antioxidants play an important role in the biosystems by scavenging the free radicals generated during the biological processes [8]. 
Since the use of synthetic antioxidants has been limited because of their toxicities, research is now directed toward antioxidants of natural origin [9].

Consequently, within the last years, an increasing number of studies have been focused on the use of plant extracts to obtain metallic and metal oxide nanoparticles with controlled size and shape through a green synthesis route [10]. It has been reported that biosynthetic routes can actually provide the nanoparticles with a better defined size and morphology than some of the physicochemical methods of production [11].

Plant extracts contain different concentrations and combinations of biocompounds and can act both as reducing and capping agents in the synthesis process of nanoparticles [10]. Garlic (Allium sativum), rosemary (Rosmarinus officinalis) and basil (Ocimum basilicum) are frequently used culinary plants. The phytochemical and pharmacological studies of Allium sativum, Rosmarinus officinalis and Ocimum basilicum extracts reveal that they are the biocompounds in rich resources and are endowed with antioxidant and therapeutic activities [12-14]. $R$. officinalis is rich in antioxidant compounds such as carnosic acid, carnosol, abietane diterpenes, rosmarinic acid, hydroxycinnamic acid, caffeic acid, and ursolic acid, which are responsible for various biological activities [15]. O. basilicum contains phenolic compounds and flavonoids such as cinnamic acid, caffeic acid, sinapic acid, and ferulic acid, which are potent antioxidants, free radical scavengers, and metal chelators [16]. A. sativum is rich in $\gamma$-glutamylcysteine and other sulfur-containing compounds, and a wide range of primary and secondary non-sulfur biomolecules such as steroidal glycosides, essential oil, flavonoids, anthocyanins, vitamins (B1, B2, B6, C and E), biotin, nicotinic acid, fatty acids, glycolipids, phospholipids and essential amino acids [17]. A. sativum plant extracts have been used for synthesis of $\mathrm{Au}$ [18], Ag [19] and $\mathrm{ZnO}$ [20] nanoparticles. The synthesis of $\mathrm{Au}$ [21], $\mathrm{Ag}$ [22] and $\mathrm{ZnO}$ [23] nanoparticles using $O$. basilicum plant extracts has also been reported. Ag nanoparticles have been synthesized using $R$. officinalis leaf extracts [15, 24]. Gunalan et al. [6] have reported on the toxicity of chemically and biologically (using aloe extract) synthesized $\mathrm{ZnO}$ NPs against plant and human pathogens.

The present work focuses on obtaining of ZnO NPs with improved antioxidant and antibacterial activities through a biosynthetic route using water extracts of A. sativum, $R$. officinalis and $O$. basilicum. The comparative evaluation of the antioxidant and antibacterial activities of chemically and green synthesized $\mathrm{ZnO}$ NPs was performed. The properties of as-synthesized ZnO NPs have been studied by adopting various characterization methods.

\section{Experimental}

\subsection{Materials}

Zinc nitrate hexahydrate $\left(\mathrm{Zn}\left(\mathrm{NO}_{3}\right)_{2} \cdot 6 \mathrm{H}_{2} \mathrm{O}, 98 \%\right)$ and 2,2diphenyl-1-picrylhydrazyl hydrate (DPPH) were purchased from Sigma-Aldrich. Oxalic acid dihydrate $\left(\mathrm{H}_{2} \mathrm{C}_{2} \mathrm{O}_{4} \cdot 2 \mathrm{H}_{2}\right.$ $\mathrm{O})$ and solvents: ethanol and methanol (HPLC grade) were procured from Merck. The fresh vegetal material was supplied from the local market. Ultrapure water and ethanol were used for washing purposes. All the chemicals and reagents were used as received without further purification.

\subsection{Synthesis of $\mathrm{ZnO}$ Nanoparticles}

The vegetal material/ultrapure water ratio used for preparation of extracts was 20:100 (w/v). The synthesis of $\mathrm{ZnO}$ NPs by biological method (using aqueous extracts of $A$. sativum bulbs and leaves of $R$. officinalis and $O$. basilicum) was carried out using a modified version of the experimental procedure reported in a previous paper by Rajiv et al. [25]. In this purpose, the fresh and finely sliced plant material was subjected to boiling at $70-80{ }^{\circ} \mathrm{C}$ for $20 \mathrm{~min}$, the extract was filtered, and its final volume was adjusted to $100 \mathrm{~mL}$ by washing the vegetal residue with ultrapure water. For the synthesis of $\mathrm{ZnO} \mathrm{NPs}$, a portion of $20 \mathrm{~mL}$ of aqueous plant extract was heated at $85-90{ }^{\circ} \mathrm{C}$, followed by addition of $2 \mathrm{~g}$ of $\mathrm{Zn}\left(\mathrm{NO}_{3}\right)_{2} \cdot 6 \mathrm{H}_{2} \mathrm{O}$ under continuous magnetic stirring at $90{ }^{\circ} \mathrm{C}$ for $3 \mathrm{~h}$. The reaction mixture was centrifuged $(7000 \mathrm{r} /$ min, $22^{\circ} \mathrm{C}, 15 \mathrm{~min}$ ): the liquid on top was transferred in a different container and heated at $150{ }^{\circ} \mathrm{C}$ for $2 \mathrm{~h}$, and the extract residue at the bottom of centrifuge tube was discarded. Finally, after heating, a dried precipitate was obtained, which was washed with ethanol, dried at room temperature and grinded to obtain fine powder. Depending upon the type of plant extract used in the synthesis, different colors of the precipitates were observed: dark brown (garlic) and yellow-orange (rosemary and basil). The obtained powders were calcined at $425{ }^{\circ} \mathrm{C}$ for $90 \mathrm{~min}$, and finally white powders were obtained.

For comparative evaluation, $\mathrm{ZnO}$ nanopowder was chemically prepared by coprecipitation of a $0.4 \mathrm{~mol} / \mathrm{L}$ aqueous solution of $\mathrm{Zn}\left(\mathrm{NO}_{3}\right)_{2} \cdot 6 \mathrm{H}_{2} \mathrm{O}$ with the same volume of a $0.4 \mathrm{~mol} / \mathrm{L}$ solution of $\mathrm{H}_{2} \mathrm{C}_{2} \mathrm{O}_{4} \cdot 2 \mathrm{H}_{2} \mathrm{O}$ at room temperature [26]. The obtained white mass was dried at room temperature, grinded and calcined at $425{ }^{\circ} \mathrm{C}$ for $90 \mathrm{~min}$.

The green synthesized $\mathrm{ZnO}$ NPs were denoted as follows: $\mathrm{ZnO}(\mathrm{g})-\mathrm{ZnO}$ synthesized using garlic (A. sativum) extract, $\mathrm{ZnO}(\mathrm{b})-\mathrm{ZnO}$ synthesized using basil (O. basilicum) extract, $\mathrm{ZnO}(\mathrm{r})$ - $\mathrm{ZnO}$ synthesized using rosemary $(R$. officinalis) extract, while chemically synthesized $\mathrm{ZnO}$ was denoted as $\mathrm{ZnO}$ (chem). 


\subsection{Characterization Methods}

$\mathrm{X}$-ray diffraction (XRD) patterns were recorded using a high-resolution Bruker D8 Advance diffractometer with $\mathrm{Cu}$ $\mathrm{X}$-ray tube and incident beam $\mathrm{Ge}$ (111) monochromator $(\lambda=0.154056 \mathrm{~nm})$.

The average size and size distribution of the nanoparticles were determined by transmission electron microscopy (TEM, Hitachi H-7650, Japan, 120 kV).

Electron paramagnetic resonance (EPR) measurements of the powder samples were taken with a Bruker ELEXSYS 500 spectrometer in X-band $(9.52 \mathrm{GHz})$. The spectra were measured at room temperature using equal quantities of the samples. The spectrum processing was performed by Bruker Xepr software.

The Fourier transform infrared (FTIR, JASCO 6100) spectroscopy was obtained with the $\mathrm{KBr}$ pellet technique in the $4000-400 \mathrm{~cm}^{-1}$ spectral region and a resolution of $2 \mathrm{~cm}^{-1}$. Ultrapure deionized water $(18.2 \mathrm{M} \Omega \mathrm{cm})$ from a Milli-Q analytical reagent-grade water purification system (Millipore) was used.

\subsection{Antioxidant Activity}

Antioxidant activity was performed by DPPH method following a modified version of the experimental procedure presented in a previous work [7].

For this purpose, $20 \mathrm{mg}$ of the powdered $\mathrm{ZnO}$ NPs was dispersed into a glass vial containing $1.3 \mathrm{~mL}$ DPPH (100 $\mu \mathrm{mol} / \mathrm{L}$ in methanol). The DPPH radical has a deep violet color in solution, and gradually it becomes colorless or pale yellow in the presence of ZnO NPs, which allows visual monitoring of the reaction [7].

A control sample (DPPH in methanol blank) was maintained without addition of the powder samples. The surface reaction between the ZnO NPs and DPPH reagent was enhanced by mild magnetic stirring. The suspensions were centrifuged, and the supernatant was withdrawn every 30 min and analyzed by EPR spectroscopy.

The scavenging percentage was calculated using the formula:

DPPH scavenging $(\%)=\frac{I}{I_{0}} \times 100$.

where $I_{0}$ and $I$ represent the initial and the changed integral intensity of the DPPH spectrum, respectively.

\subsection{Antibacterial Activity}

\subsubsection{Bacterial Strains and Culture Conditions}

Six bacterial strains, namely Staphylococcus aureus ATCC-25923, Bacillus subtilis ATCC-12228, Listeria monocytogenes ATCC-19115, Escherichia coli ATCC25922, Salmonella typhimurium ATCC-14028 and Pseudomonas aeruginosa ATCC-27853, were used in this study. The cultures were maintained on Mueller-Hinton agar (bioMérieux, Marcy l'Etoile, France). The bacteria were cultured overnight into $5 \mathrm{~mL}$ Mueller-Hinton broth (bioMérieux, Marcy l'Etoile, France) in a shaker incubator (Heidolph Inkubator 1000 coupled with Heidolph Unimax 1010, Germany) at $37{ }^{\circ} \mathrm{C}, 150 \mathrm{r} / \mathrm{min}$ until the culture reached an $\mathrm{OD}_{600}$ of 0.1 (Nanodrop Spectrophotometer ND-1000, USA) corresponding to $10^{9} \mathrm{CFU} / \mathrm{mL}$. Before incubation with materials, the cultures were diluted to $10^{5} \mathrm{CFU} / \mathrm{mL}$.

\subsubsection{Antibacterial Efficiency Tests}

$\mathrm{ZnO}$ NPs were tested in vitro for their antimicrobial activity against strains by the agar diffusion method [27]. The tested materials were dissolved in dimethyl sulfoxide (DMSO) to prepare stock solutions of $100 \mu \mathrm{g} / \mathrm{mL}$. Furthermore, $100 \mu \mathrm{L}$ of bacteria inoculums was spread over the plates containing sterile Muller-Hinton agar. Paper filter disks $(6 \mathrm{~mm})$ were impregnated with $20 \mu \mathrm{L}$ of stock solution. The plates were maintained at room temperature for $30 \mathrm{~min}$ to allow the diffusion of the solutions and then incubated at $37^{\circ} \mathrm{C}$ for $24 \mathrm{~h}$. Finally, the inhibition zone around the disk was measured. Each experiment was made in triplicate, and the inhibition zones are expressed as the mean \pm standard deviation (SD).

\subsubsection{Minimum Inhibitory Concentration}

The microdilution method was employed for minimum inhibitory concentration test. Media was placed into each 96 wells of the microplates. Sample solutions at high concentration $(100 \mu \mathrm{g} / \mathrm{mL})$ were added into first rows of microplates, and twofold dilutions of the compounds were made by dispensing the solutions into the remaining wells (from 100 to $0.012 \mu \mathrm{g} / \mathrm{mL}$ ). Ten microliters of culture suspensions was inoculated into all the wells. The sealed microplates are incubated at $37{ }^{\circ} \mathrm{C}$ for $18 \mathrm{~h}$. $\mathrm{ZnO}$-free solution was used as control. The lowest concentration of the $\mathrm{ZnO}$ that completely inhibited macroscopic growth was determined, and the minimum inhibitory concentrations (MICs) were recorded by spectroscopic method $(600 \mathrm{~nm})$ with a microplate reader Biotek Synergy HT. As a confirmation test, after microplate incubation for $24 \mathrm{~h}$ at $37{ }^{\circ} \mathrm{C}, 50 \mu \mathrm{L}$ from each well were spread on solidified growth media plates and were further incubated for $24 \mathrm{~h}$. Growth-free plates confirmed that the used concentration inhibited the bacterial growth. The gentamicin antibiotic was tested at concentrations ranging between 0.0024 and $20 \mu \mathrm{g} / \mathrm{mL}$. 


\subsubsection{Statistical Analysis}

Results for three individual experiments were used to calculate the mean of diameter from inhibition zone. Analysis of variance (ANOVA) and Duncan's multiple range tests were performed to analyze the results. Significance of difference was defined at the $5 \%$ level $(P<0.05)$. All statistical analysis was carried out using GraphPad Version 4.0 (GraphPad Software Inc., San Diego, CA, USA).

\section{Results and Discussion}

Figure 1 shows the XRD patterns of chemically and biologically synthesized $\mathrm{ZnO}$ NPs using extracts from three plant species. The positions of XRD peaks show good agreement with those of the hexagonal wurtzite structure for bulk $\mathrm{ZnO}$ with lattice constants of $a=0.3249 \mathrm{~nm}$ and $c=0.5208 \mathrm{~nm}$ [JCPDS card No. 36-1451, P63mc]. The Scherrer equation applied to (101) peak was used for calculating the crystallite size. For the green synthesized $\mathrm{ZnO}$ NPs, the smallest crystallite size was obtained for $\mathrm{ZnO}(\mathrm{g})(14 \mathrm{~nm})$, followed by $\mathrm{ZnO}(\mathrm{b})(25 \mathrm{~nm})$ and $\mathrm{ZnO}(\mathrm{r})(54 \mathrm{~nm})$, while the crystallite size of chemically synthesized $\mathrm{ZnO}$ NPs was $25 \mathrm{~nm}$.

The morphological characteristics of the nanoparticles revealed by TEM are shown in Fig. 2. The TEM images of $\mathrm{ZnO}$ NPs illustrate the presence of nanocrystalline particles and aggregation with various shapes and sizes depending on the method for nanoparticle synthesis. ZnO NPs prepared by chemical method are spherical in shape with mean size of $26 \mathrm{~nm}$ (Fig. 2a), whereas the $\mathrm{ZnO}(\mathrm{g}$ ) and $\mathrm{ZnO}$ (b) nanoparticles have an almost spherical shape and

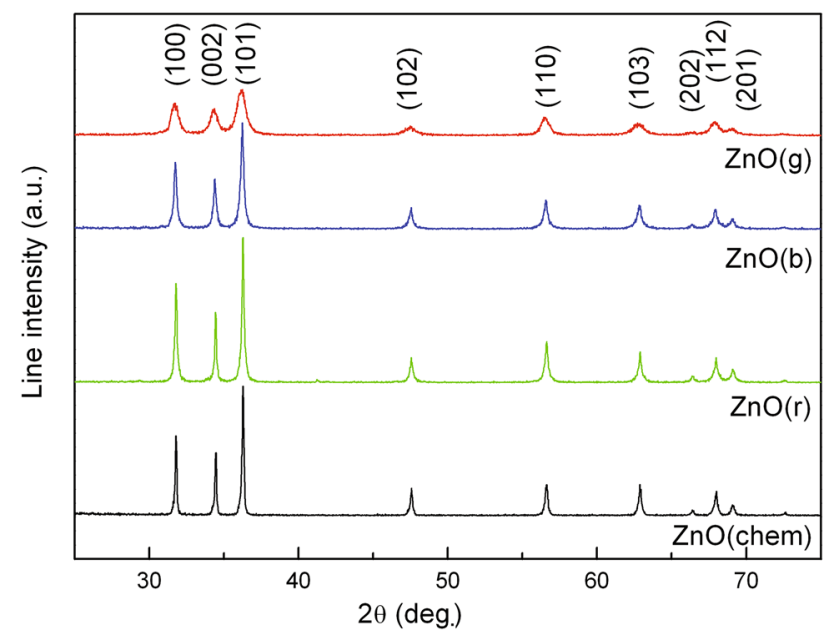

Fig. 1 XRD patterns of $\mathrm{ZnO}(\mathrm{chem})$ and $\mathrm{ZnO}$ NPs synthesized using aqueous extracts of garlic (A. sativum), basil (O. basilicum) and rosemary (R. officinalis): $\mathrm{ZnO}(\mathrm{g}), \mathrm{ZnO}(\mathrm{b}), \mathrm{ZnO}(\mathrm{r})$ mean grain sizes of $14 \mathrm{~nm}$ and $27 \mathrm{~nm}$, respectively (Fig. 2b, c). In the case of $\mathrm{ZnO}(\mathrm{r})$ sample, the nanoparticles predominantly assemble into aggregates of elongated shape (Fig. 2d).

The mean particle size of $\mathrm{ZnO}$ nanoparticles obtained from TEM analysis is consistent with the average crystallite size estimated by XRD analysis.

FTIR analysis was carried out to identify the possible biomolecules involved in the biosynthesis of $\mathrm{ZnO}$ NPs. The FTIR spectra of the analyzed samples are displayed in Fig. 3.

The FTIR spectrum of chemical $\mathrm{ZnO}$ consists of a band around $1636 \mathrm{~cm}^{-1}$ due to $\mathrm{O}-\mathrm{H}$ bending of absorbed water and an intense peak at $500 \mathrm{~cm}^{-1}$ specific to $\mathrm{ZnO}$ stretching frequency of $\mathrm{Zn}-\mathrm{O}$ bonds [28].

Compared with chemical $\mathrm{ZnO}$, the FTIR spectra of biosynthesized $\mathrm{ZnO}$ samples show additional bands at different wavenumbers due to the presence of various functional groups, which are related to the by-products resulting from the usage of A. sativum, R. officinalis and $O$. basilicum aqueous extracts. The FTIR spectrum of $\mathrm{ZnO}(\mathrm{g})$ contains bands centered at: $1385 \mathrm{~cm}^{-1}$ attributed to the $\mathrm{C}-\mathrm{O}-\mathrm{H}$ bending of carboxylic group [18], $1118 \mathrm{~cm}^{-1}$ attributed to $\mathrm{S}=\mathrm{O}$ bond [29] and a lower frequency band at $870 \mathrm{~cm}^{-1}$ which could be assigned to $\mathrm{S}-\mathrm{C}$ absorption of organosulfur compounds present in the garlic extract [18].

The FTIR spectrum of $\mathrm{ZnO}(\mathrm{b})$ is composed of bands situated at the wavenumbers: $1737 \mathrm{~cm}^{-1}$ attributed to the stretching vibrations of $\mathrm{C}=\mathrm{O}, 1639 \mathrm{~cm}^{-1}$ corresponding to the $\mathrm{N}-\mathrm{H}$ bending of primary amines, $1490 \mathrm{~cm}^{-1}$ related to the $\mathrm{C}-\mathrm{C}$ stretching of aromatic ring structure, $1367 \mathrm{~cm}^{-1}$ due to the $\mathrm{C}-\mathrm{N}$ stretching of aromatic amine group and $1020 \mathrm{~cm}^{-1}$ attributed to the $\mathrm{C}-\mathrm{C}$ stretching of alcohols, carboxylic acids, ethers and esters [22].

Most of the bands in the IR spectrum of $\mathrm{ZnO}(\mathrm{r})$ are characteristic of the flavonoids and terpenoids from the leaf extract. The low absorption band located at $1574 \mathrm{~cm}^{-1}$ corresponds to $\mathrm{C}=\mathrm{C}$ stretching modes of vibration $[15,30]$. The bands at 1490, 1382 and $1268 \mathrm{~cm}^{-1}$ may be attributed to $\mathrm{C}-\mathrm{N}$ stretching of the aromatic amine group, $\mathrm{C}-\mathrm{O}-\mathrm{C}$ stretching modes of vibration and $\mathrm{C}-\mathrm{O}$ stretching of esters, ethers and phenols, respectively [15]. The absorption bands centered at around 1027 and $1118 \mathrm{~cm}^{-1}$ may arise from the $\mathrm{C}-\mathrm{O}$ and $\mathrm{C}-\mathrm{N}$ stretching vibrations of the aliphatic amines or alcohols/phenols due to the presence of polyphenols in the rosemary extract [24]. Both $\mathrm{ZnO}(\mathrm{b})$ and $\mathrm{ZnO}(\mathrm{r})$ samples show an absorption peak around $840 \mathrm{~cm}^{-1}$ probably due to $\mathrm{O}-\mathrm{H}$ functional group [31].

The active biocompounds from the plant extracts, evidenced by FTIR spectra, could be responsible for the reduction and stabilization of the nanoparticles (phenolic compounds, organosulfur compounds, amino acids, etc.). 


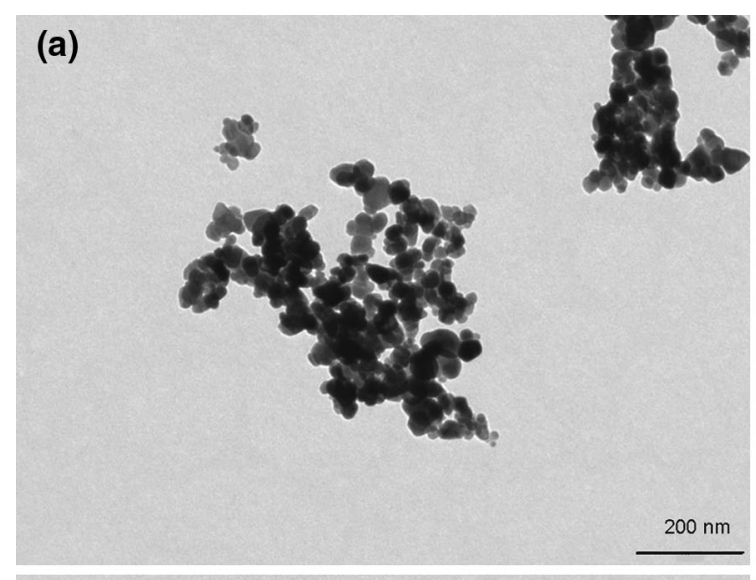

(b)

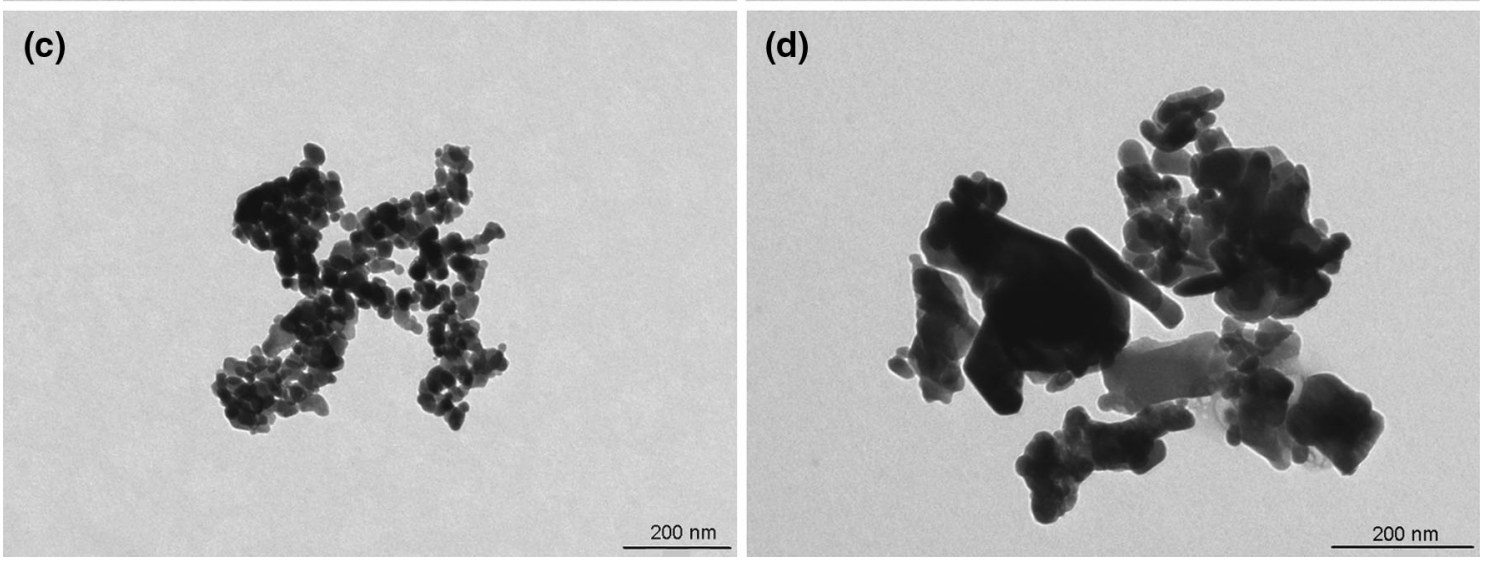

Fig. 2 TEM images of $\mathrm{ZnO} N \mathrm{NP}$ : a $\mathrm{ZnO}($ chem $)$, b $\mathrm{ZnO}(\mathrm{g})$, $\mathbf{c} \mathrm{ZnO}(\mathrm{b})$, d $\mathrm{ZnO}(\mathrm{r})$

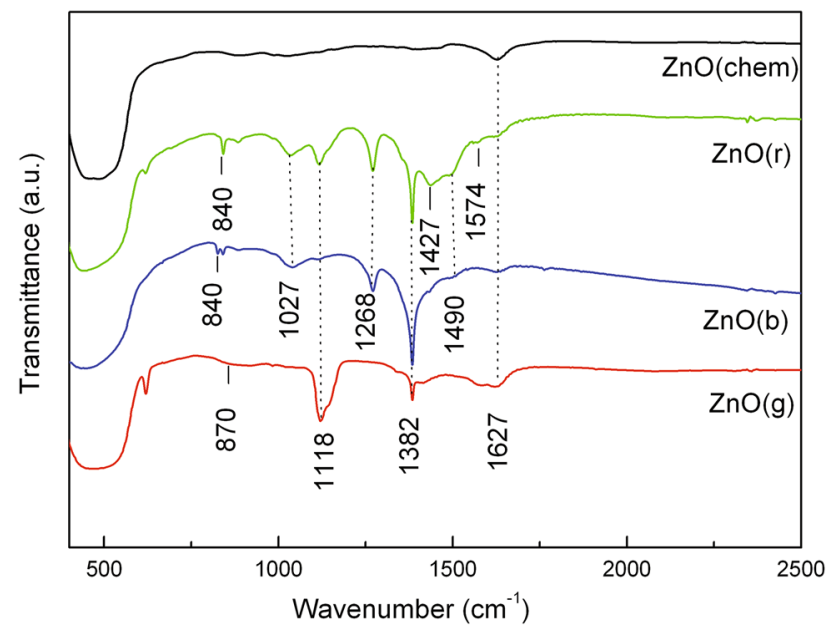

Fig. 3 FTIR spectra of $\mathrm{ZnO}$ (chem) and $\mathrm{ZnO}$ NPs synthesized using extracts of garlic (A. sativum), basil (O. basilicum) and rosemary $(R$. officinalis): $\mathrm{ZnO}(\mathrm{g}), \mathrm{ZnO}(\mathrm{b}), \mathrm{ZnO}(\mathrm{r})$

Previous studies have shown that the phenolic groups of molecules are responsible for the reduction process and the stability of $\mathrm{ZnO}$ NPs is due to the free amino and carboxylic groups [32].

The presence of lattice defects and possible impurities was investigated by EPR spectroscopy. The EPR spectra of the samples are shown in Fig. 4. It can be seen in Fig. 4 that the EPR signal of $\mathrm{ZnO}$ sample is composed of two sharp signals centered at $3394 \mathrm{G}(g \sim 2.03)$ and $3460 \mathrm{G}$ $(g \sim 1.96)$. These signals are attributed in the literature to the lattice defects appearing in the sample.

The EPR signal with $g_{\text {eff }} \sim 2.03$ was usually assigned to negatively charged zinc vacancy-interstitial zinc $\left(V_{\mathrm{Zn}}^{-}\right.$: $\mathrm{Zn}_{i}^{0}$ ) complexes [33]. The second EPR signal could be attributed to the axial singly ionized oxygen vacancies $V_{\mathrm{O}}^{+}$ $[33,34]$.

Upon analysis of EPR spectra of the green synthesized $\mathrm{ZnO}$ samples, the characteristic lines of $\mathrm{ZnO}(\mathrm{chem})$ can also be identified. These lines are more intense than in the case of $\mathrm{ZnO}$ (chem) sample, suggesting the presence of an increased number of lattice defects. Since the linewidth remains constant, the signal intensity of the EPR signal due to defects could be assumed as proportional to the number of EPR active species involved in the resonance absorption. The highest concentration of defects was noticed for $\mathrm{ZnO}(\mathrm{g})$, followed by $\mathrm{ZnO}(\mathrm{b})$ and $\mathrm{ZnO}(\mathrm{r})$.

By superimposing these defect signals on $\mathrm{ZnO}(\mathrm{g})$ and $\mathrm{ZnO}(\mathrm{r})$ samples, the typical EPR spectrum of isolated $\mathrm{Mn}^{2+}$ ions could be observed-a spectrum composed of six hyperfine lines $(A=75 \mathrm{G})$ centered around $g \sim 2.00$ 


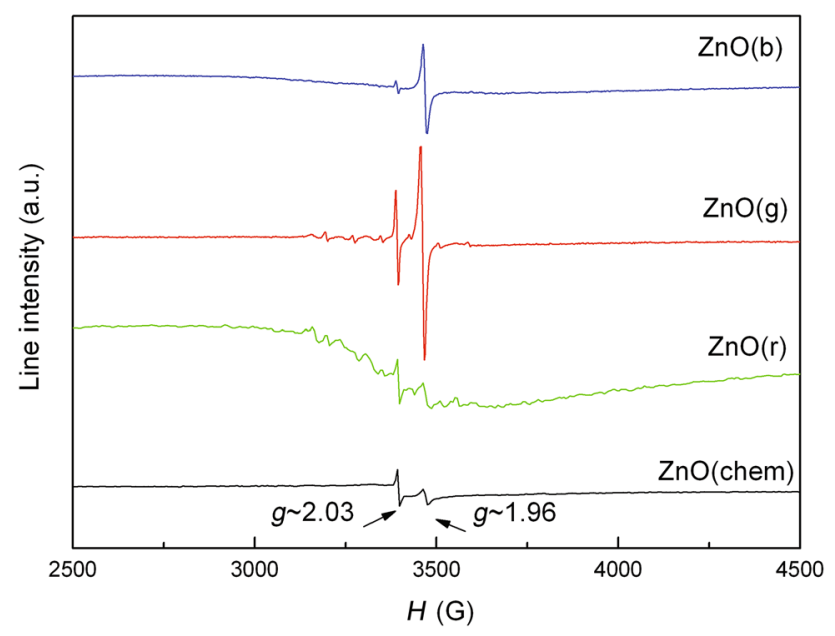

Fig. 4 EPR spectra of $\mathrm{ZnO}$ NPs: $\mathrm{ZnO}(\mathrm{chem}), \mathrm{ZnO}(\mathrm{g}), \mathrm{ZnO}(\mathrm{b})$, $\mathrm{ZnO}(\mathrm{r})$

[35]. Further, a system of the lines of lower intensity identified as the so-called forbidden transitions appears [36].

Moreover, $\mathrm{ZnO}(\mathrm{r})$ sample presents a supplementary broad EPR line centered at $3400 \mathrm{G}(g \sim 2.02489)$ and extended over $\sim 400 \mathrm{G}$. This line is assigned either to some $\mathrm{Mn}$ ions in dipolar interaction or to the presence of $\mathrm{Mn}$ clusters [37]. The presence of $\mathrm{Mn}^{2+}$ ions could be due to the use of aqueous extracts during synthesis process. It is known that manganese is an essential element and micronutrient in photosynthetic green plants [38].

An important mechanism of antioxidant activity is the scavenging effect, and this effect was evaluated by EPR using DPPH stable free radicals. DPPH is relatively stable nitrogen-centered free radical that easily accepts an electron or a hydrogen radical to become a stable diamagnetic molecule. Depending on the number of electrons taken up, the solution loses its color. Substance capable of donating electrons/hydrogen atom is able to convert DPPH (purple) into their nonradical form 1,1-diphenyl-2-picrylhydrazine (yellow), a reaction which can be easily followed by EPR spectroscopy [39]. The EPR signal of DPPH is composed of a triplet lines centered at $g \sim 2.00$ and with a linewidth of $7 \mathrm{G}$. The EPR signal intensity is reduced in time after addition of $\mathrm{ZnO}$ powder samples to the methanolic DPPH solution.

The evolution in time of the EPR signal intensity for the mixture of methanolic $\mathrm{DPPH}$ and $\mathrm{ZnO}(\mathrm{g})$ powder is presented in Fig. 5a. The evaluation of DPPH radical scavenging activity in time for all analyzed $\mathrm{ZnO}$ samples was also performed (Fig. 5b).

Experimental data demonstrate a higher radical scavenging activity of the ZnO NPs prepared with plant extracts in comparison with chemically synthesized ZnO NPs. The
DPPH radical scavenging activity decreased as follows: $\mathrm{ZnO}(\mathrm{g})>\mathrm{ZnO}(\mathrm{b})>\mathrm{ZnO}(\mathrm{r})$.

The antioxidant property of $\mathrm{ZnO}$ nanoparticles could be due to the transfer of electron density located at oxygen to the odd electron located at nitrogen atom in DPPH. This property depends on the structural configuration of oxygen atom, and it determines the thermal stability of nanoparticle by its available free energy of oxides [40].

For $\mathrm{ZnO}$ NPs synthesized using plant extracts, the antioxidant efficacy against DPPH is probably derived also from the electrostatic attraction between negatively charged bioactive compounds $\left(\mathrm{COO}^{-}, \mathrm{O}^{-}\right)$of plant extracts and positively charged nanoparticles $(\mathrm{ZnO}=$ $\mathrm{Zn}^{2+}+\mathrm{O}^{2-}$ ) [41]. ZnO NPs bound to the phytochemicals, and their bioactivity increases synergistically.

The differences in the scavenging activity of the $\mathrm{ZnO}$ prepared with different plant extracts could be related to the fact that the nanoparticles have different sizes and consequently different specific surfaces according to the plant extract used in the synthesis process. The $\mathrm{ZnO}(\mathrm{g})$ samples which have the smallest nanoparticle size showed the highest radical scavenging activity. Similar behavior was observed for Au nanoparticles, and it has been demonstrated that the insignificant scavenging activity in a solution of the nanocomposite containing $\mathrm{Au}$ nanoparticles of the maximum size is due to their lower specific surface $[42,43]$.

Antibacterial activity of $\mathrm{ZnO}$ NPs against different bacterial strains was measured as diameter of inhibition zone (agar diffusion method) and minimum inhibitory concentration (MIC), and the data are presented in Table 1. The gentamicin antibiotic was used as control. It was observed that the size of inhibition zone was different according to the type of bacteria, the type of plant extract and the synthesis method. In our study, ZnO NPs synthesized using plant extracts showed a greater zone of inhibition as compared to chemical ZnO NPs (Table 1). The maximum zones of inhibition were observed against the pathogen $S$. aureus for $\mathrm{ZnO}$ NPs synthesized with the plant extracts: garlic $(22 \pm 1.3 \mathrm{~mm})$, basil $(19.3 \pm 0.7 \mathrm{~mm})$ and rosemary $(19.2 \pm 0.3 \mathrm{~mm})$. Among the green synthesized $\mathrm{ZnO}$ NPs, the garlic extract-mediated synthesized ZnO NPs showed the most significant antimicrobial activity against the selected bacterial strains with zone inhibition diameters in the range from $13.8 \mathrm{~nm}$ to $22 \mathrm{~mm}$, with enhanced activity against $S$. aureus $(22 \pm 1.3 \mathrm{~mm}), \quad$ E. coli $(18 \pm 0.2 \mathrm{~mm})$ and $P$. aeruginosa $(17.9 \pm 0.1 \mathrm{~mm})$. The lowest zone of inhibition occurred in $S$. typhimurium $(8.2 \pm 0.6 \mathrm{~mm})$ for $\mathrm{ZnO}$ NPs synthesized with basil extract (Table 1).

According to the literature, the antibacterial activity could be explained on the basis of reactive oxygen species (ROS) such as $\mathrm{H}_{2} \mathrm{O}_{2}$, hydroxyl radicals, singlet oxygen, 

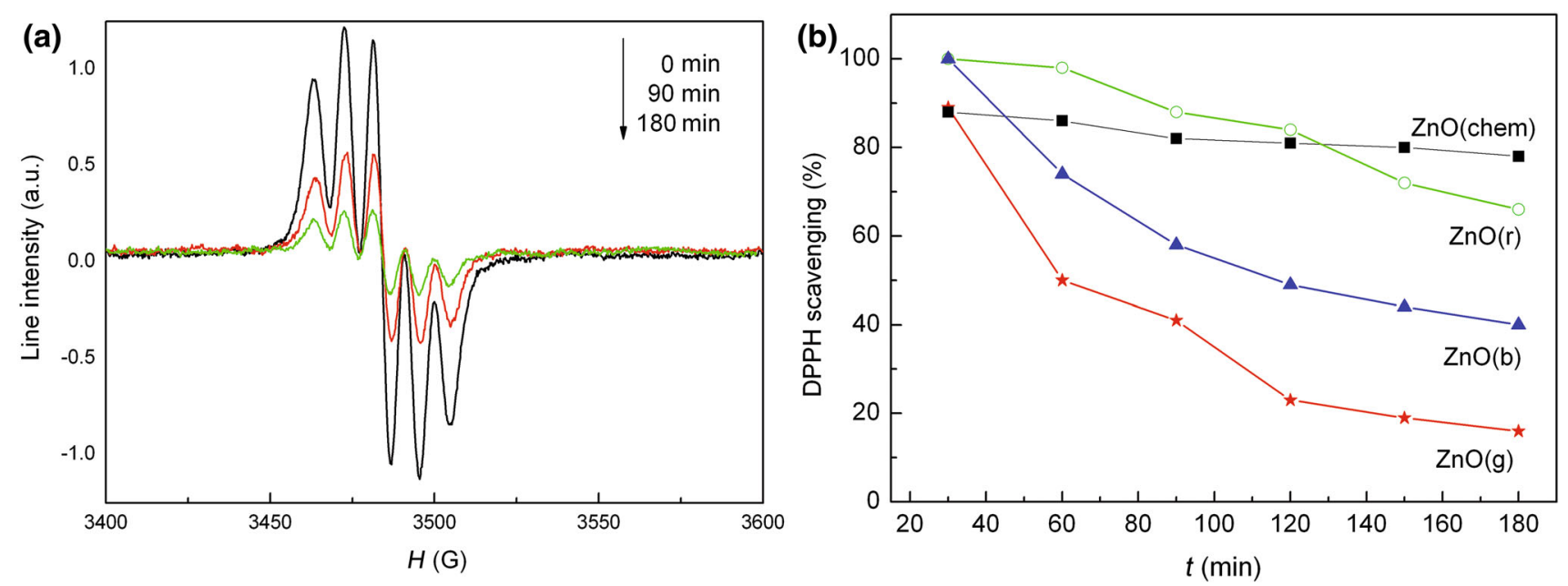

Fig. 5 a Time-dependent evolution of the EPR spectrum of the methanolic DPPH solution after dispersing the ZnO NPs synthesized using garlic (A. sativum) extract, $\mathbf{b}$ antioxidant activity of $\mathrm{ZnO} \mathrm{NPs}$ at different time intervals

Table 1 Antibacterial activity of $\mathrm{ZnO}$ powders against bacterial strains

\begin{tabular}{|c|c|c|c|c|c|c|}
\hline \multirow[t]{2}{*}{ Sample } & \multicolumn{6}{|c|}{ Bacterial strains } \\
\hline & S. aureus & S. typhimurium & E. coli & L. monocytogenes & B. subtilis & P. aeruginose \\
\hline \multicolumn{7}{|l|}{$\mathrm{ZnO}$ (chem) } \\
\hline Diameter $(\mathrm{mm})$ & $16.3 \pm 0.2^{\mathrm{c}}$ & $8.9 \pm 0.1^{\mathrm{c}}$ & $13.1 \pm 0.4^{\mathrm{c}}$ & $9.3 \pm 0.5^{\mathrm{d}}$ & $8.7 \pm 0.8^{c}$ & $12.6 \pm 0.7^{\mathrm{b}}$ \\
\hline $\mathrm{MIC}(\mu \mathrm{g} / \mathrm{mL})$ & 12.5 & 1.56 & 3.12 & 12.5 & 6.24 & 0.78 \\
\hline \multicolumn{7}{|l|}{$\mathrm{ZnO}(\mathrm{b})$} \\
\hline Diameter $(\mathrm{mm})$ & $19.3 \pm 0.7^{\mathrm{b}}$ & $8.2 \pm 0.6^{\mathrm{c}}$ & $13.2 \pm 0.6^{\mathrm{c}}$ & $11.4 \pm 0.8^{\mathrm{c}}$ & $9.3 \pm 0.6^{\mathrm{c}}$ & $12.4 \pm 0.5^{\mathrm{b}}$ \\
\hline $\mathrm{MIC}(\mu \mathrm{g} / \mathrm{mL})$ & 1.56 & 6.25 & 3.12 & 6.25 & 0.78 & 0.78 \\
\hline \multicolumn{7}{|l|}{$\mathrm{ZnO}(\mathrm{r})$} \\
\hline Diameter (mm) & $19.2 \pm 0.3^{\mathrm{b}}$ & $9.3 \pm 0.8^{\mathrm{c}}$ & $12.7 \pm 0.5^{\mathrm{c}}$ & $11.5 \pm 0.9^{c}$ & $9 \pm 0.6^{c}$ & $12.5 \pm 0.6^{\mathrm{b}}$ \\
\hline MIC $(\mu \mathrm{g} / \mathrm{mL})$ & 0.39 & 1.56 & 1.56 & 6.25 & 0.78 & 0.78 \\
\hline \multicolumn{7}{|l|}{$\mathrm{ZnO}(\mathrm{g})$} \\
\hline Diameter $(\mathrm{mm})$ & $22 \pm 1.3^{\mathrm{a}}$ & $14 \pm 0.6^{\mathrm{b}}$ & $18 \pm 0.2^{\mathrm{b}}$ & $15.1 \pm 0.5^{\mathrm{b}}$ & $13.8 \pm 0.5^{\mathrm{b}}$ & $17.9 \pm 0.1^{\mathrm{a}}$ \\
\hline $\mathrm{MIC}(\mu \mathrm{g} / \mathrm{mL})$ & 0.09 & 0.39 & 0.19 & 0.78 & 0.19 & 0.19 \\
\hline \multicolumn{7}{|c|}{ Gentamicin $(10 \mu \mathrm{g} / \mathrm{mL})$} \\
\hline Diameter $(\mathrm{mm})$ & $22.1 \pm 0.7^{\mathrm{a}}$ & $21.3 \pm 0.1^{\mathrm{a}}$ & $20.2 \pm 0.1^{\mathrm{a}}$ & $18.6 \pm 0.6^{\mathrm{a}}$ & $22.4 \pm 0.6^{\mathrm{a}}$ & $12.6 \pm 0.4^{\mathrm{b}}$ \\
\hline MIC $(\mu \mathrm{g} / \mathrm{mL})$ & 0.15 & 1.2 & 1.2 & 0.6 & 0.3 & 0.6 \\
\hline
\end{tabular}

Means $(n=3) \pm$ SD. Means with different letter in a column are significantly different $(p<0.05)$

and $\mathrm{Zn}^{2+}$ ions released on the surface of $\mathrm{ZnO}$, which cause severe damage to bacteria [44-46]. The generation of hydrogen peroxide $\left(\mathrm{H}_{2} \mathrm{O}_{2}\right)$ from the surface of $\mathrm{ZnO}$ is considered as an effective mean for the inhibition of bacterial growth according to some studies [47]. It has been reported that $\mathrm{ZnO}$ can be activated by both UV and visible light and consequently, electron-hole pairs $\left(\mathrm{e}^{-} / \mathrm{h}^{+}\right)$can be created. The generation of $\mathrm{H}_{2} \mathrm{O}_{2}$ is explained as follows: the holes split the $\mathrm{H}_{2} \mathrm{O}$ molecule from the suspension of $\mathrm{ZnO}$ into $\mathrm{OH}^{-}$and $\mathrm{H}^{+}$. Furthermore, dissolved oxygen molecules are converted to superoxide radical anions $\left(\mathrm{O}_{2}^{--}\right)$ which react with hydrogen ion $\left(\mathrm{H}^{+}\right)$to produce $\mathrm{HO}_{2}$ radicals. The collision of these hydroxyl radicals with electrons will produce hydrogen peroxide anions $\mathrm{HO}_{2}^{-}$, which react with hydrogen to generate $\mathrm{H}_{2} \mathrm{O}_{2}$ molecules. The $\mathrm{H}_{2} \mathrm{O}_{2}$ molecules thus generated can penetrate the cell membrane and kill the bacteria [48, 49].

The $\mathrm{e}^{-} / \mathrm{h}^{+}$pair recombination minimizes the chances of ROS generation. Lattice defects play an important role in the inhibiting $\mathrm{e}^{-} / \mathrm{h}^{+}$pair recombination process [50]. As can be observed from EPR spectra, a large number of defects occur in green synthesized $\mathrm{ZnO}$ samples prepared using aqueous extracts. These defects may act as trapping centers and inhibit photoinduced $\mathrm{e}^{-} / \mathrm{h}^{+}$pair recombination 
[51] resulting in higher antibacterial activity of green synthesized ZnO NPs as compared to chemical ZnO NPs.

Other studies showed the antibacterial activity to be dependent on the particle size, specific surface area and crystallinity of $\mathrm{ZnO}$ [52-54]. From our results of MIC, it could be confirmed that the ZnO NPs synthesized using garlic extract and having the smallest nanoparticle size exhibited enhanced antibacterial activity due to the large surface area to volume ratio and surface reactivity as compared to the ZnO NPs prepared by chemical method [6].

\section{Conclusion}

In this study, the ZnO NPs were successfully prepared by a green synthesis procedure using aqueous extracts of garlic (A. sativum), rosemary ( $R$. officinalis) and basil (O. basilicum), demonstrating the enhanced bioactivity of green synthesized $\mathrm{ZnO}$ NPs by studying their antioxidant and antibacterial activities and comparison with those of chemically synthesized ZnO NPs. Data indicated also that all $\mathrm{ZnO}$ samples have a hexagonal wurtzite structure. It was found that the crystallite dimensions and the nanoparticle size were influenced by the plant extract used in the green synthesis procedure. The size of particles ranged between 14 and $27 \mathrm{~nm}$. It proved that the ZnO NPs are an effective antibacterial agent against common pathogenic microorganisms. It is believed that the use of plant extracts in the synthetic procedure results in enhanced antibacterial and antioxidant properties of $\mathrm{ZnO}$ NPs.

Acknowledgments This work was supported by the Romanian Ministry of Education and Research within the Nucleu Programme (Project PN 09-44).

\section{References}

[1] M.G. Nair, M. Nirmala, K. Rekha, A. Anukaliani, Mater. Lett. 65, 1797 (2011)

[2] H.J. Park, S.H. Kim, H.J. Kim, S.H. Choi, Plant Pathol. J. 22, 25 (2006)

[3] R. Prasad, V. Kumar, K.S. Prasad, Afr. J. Biotechnol. 13, 705 (2014)

[4] A. Yadav, V. Prasad, A.A. Kathe, R. Sheela, Y. Deepti, C. Sundaramoorthy, N. Vigneshwaran, Bull. Mater. Sci. 29, 641 (2006)

[5] R. Lamb, I.I. Zhang, A. Jones, R. Postle, Proc. 83rd TIWC (Shanghai, 2004), p. 682

[6] S. Gunalan, R. Sivaraj, V. Rajendran, Prog. Nat. Sci. Mater. Int. 22, 693 (2012)

[7] D. Das, B.C. Nath, P. Phukon, A. Kalita, S.K. Dolui, Colloids Surf. B 111, 556 (2013)

[8] J.P. Saikia, S. Paul, B.K. Konwar, S.K. Samdarshi, Colloids Surf. B 78, 146 (2010)

[9] P.C. Nagajyothi, S.J. Cha, I.J. Yang, T.V.M. Sreekanth, K.J. Kim, H.M. Shin, J. Photochem. Photobiol. B 146, 10 (2015)
[10] A.K. Mittal, Y. Chisti, U.C. Banerjee, Biotechnol. Adv. 31, 346 (2013)

[11] P. Raveendran, J. Fu, S.L. Wallen, J. Am. Chem. Soc. 125, 13940 (2003)

[12] B. Meriga, R. Mopuri, T. MuraliKrishna, Asian Pac. J. Trop. Med. 5, 391 (2012)

[13] N. Erkan, G. Ayranci, E. Ayranci, Food Chem. 110, 76 (2008)

[14] I. Gülçin, M. Elmastat, H.Y. Aboul-Enein, Phytother. Res. 21, 354 (2007)

[15] J. Das, P. Velusamy, Mater. Res. Bull. 48, 4531 (2013)

[16] C. Jayasinghe, N. Gotoh, T. Aoki, S. Wada, J. Agric. Food Chem. 51, 4442 (2003)

[17] B. Bozin, N. Mimica-Dukic, I. Samojlik, A. Goran, R. Igic, Food Chem. 111, 925 (2008)

[18] L. Rastogi, J. Arunachalam, Adv. Mater. Lett. 4, 548 (2013)

[19] G. Von White, P. Kerscher, R.M. Brown, J.D. Morella, W. McAllister, D. Dean, C.L. Kitchens, J. Nanomater. 2012, 1 (2012)

[20] M. Stan, A. Popa, D. Toloman, A. Dehelean, I. Lung, G. Katona, Mater. Sci. Semicond. Process. 39, 23 (2015)

[21] G. Singhal, R. Bhavesh, A.R. Sharma, R.P. Singh, Adv. Sci. Eng. Med. 4, 62 (2012)

[22] G. Anuradha, B. Syama Sundar, J. Sreekanth Kumar, M.V. Ramana, Eur. J. Acad. Essays 1, 5 (2014)

[23] H.A. Salam, R. Sivaraj, R. Venckatesh, Mater. Lett. 131, 16 (2014)

[24] R.C. Fierascu, I.R. Bunghez, R. Somoghi, I. Fierascu, R.M. Ion, Rev. Roum. Chim. 59, 213 (2014)

[25] P. Rajiv, S. Rajeshwari, R. Venckatesh, Spectrochim. Acta A Mol. Biomol. Spectrosc. 112, 384 (2013)

[26] N. Brihi, A. Bouaine, A. Berbadj, G. Schmerber, S. Colis, A. Dinia, Thin Solid Films 518, 4549 (2010)

[27] C. Perez, M. Pauli, P. Bazevque, Acta Biol. Med. Exp. 15, 113 (1990)

[28] G. Xiong, U. Pal, J.G. Serrano, K.B. Ucer, R.T. Williams, Phys. Status Solidi C 3, 3577 (2006)

[29] J. Songsungkan, S. Chanthai, Int. Food Res. J. 21, 2377 (2014)

[30] C. Houlihan, C.T. Ho, S.S. Chang, J. Am. Oil Chem. 61, 1036 (1984)

[31] N. Yıldız, Ç. Ateş, M. Yılmaz, D. Demir, A. Yıldız, A. Çalımlı, Green Process. Synth. 3, 259 (2014)

[32] S.R. Senthilkumar, T. Sivakumar, Int. J. Pharm. Pharm. Sci. 6, 461 (2014)

[33] N. Vorobyeva, M. Rumyantseva, D. Filatova, E. Konstantinova, D. Grishina, A. Abakumov, S. Turner, A. Gaskov, Sens. Actuators B Chem. 182, 555 (2013)

[34] J.M. Smith, W.E. Vehse, Phys. Lett. A 31, 147 (1970)

[35] H. Beinert, G. Palmer, Adv. Enzymol. Relat. Areas Mol. Biol. 27, 105 (1965)

[36] V. Hronský, M. Rákoš, J. Belák, J. Juhár, D. Kazár, Czechoslov. J. Phys. B 28, 1277 (1978)

[37] D. Toloman, A. Mesaros, A. Popa, O. Raita, T.D. Silipas, B.S Vasile, O. Pana, L.M. Giurgiu, J. Alloys Compd. 551, 502 (2013)

[38] M.A. Morsy, Spectrosc. Int. J. 16, 371 (2002)

[39] M. Patel Rajesh, J. Patel Natvar, J. Adv. Pharm. Edu. Res. 1, 52 (2011)

[40] T. Wu, F. Yen, L. Lin, T. Tsai, C. Lin, T. Cham, Intl. J. Pharm. 346, 160 (2008)

[41] B. Kumar, K. Smita, L. Cumbal, A. Debut, Bioinorg. Chem. Appl. 2014, 523869 (2014)

[42] N.O. Yakimovich, A.A. Ezhevskii, D.V. Guseinov, L.A. Smirnova, T.A. Gracheva, K.S. Klychkov, Russ. Chem. Bull. 57, 520 (2008)

[43] A. Watanabe, M. Kajita, J. Kim, A. Kanayama, K. Takahashi, T. Maino, Y. Miyamoto, Nanotechnology 20, 1 (2009) 
[44] T. Jan, J. Iqbal, M. Ismail, A. Mahmood, J. Appl. Phys. 115, 154308 (2014)

[45] A.J. Huh, Y.J. Kwon, J. Controll. Release 156, 128 (2011)

[46] K. Feris, C. Otto, J. Tinker, D. Wingett, A. Punnoose, A. Thurber, M. Kongara, M. Sabetian, B. Quinn, C. Hanna, D. Pink, Langmuir 26, 4429 (2010)

[47] O. Yamamoto, Int. J. Inorg. Mater. 3, 643 (2001)

[48] N. Padmavathy, R. Vijayaraghavan, Sci. Technol. Adv. Mater. 9, 432 (2008)

[49] A.H. Shah, E. Manikandan, M.B. Ahamed, D.A. Mir, S.A. Mir, J. Lumin. 145, 944 (2014)

[50] A. Ozlem, E.H. Husnu, D. Caner, J. Am. Ceram. Soc. 96, 766 (2013)
[51] J. Zhao, L. Wang, X. Yan, Y. Yang, Y. Lei, J. Zhou, Y. Huang, Y. Gu, Y. Zhang, Mater. Res. Bull. 46, 1207 (2011)

[52] T. Ohira, O. Yamamoto, Y. Iida, Z. Nakagawa, J. Mater. Sci. Mater. Med. 19, 1407 (2008)

[53] C. Baker, A. Pradhan, L. Pakstis, D.J. Pochan, S.S. Ismat, J. Nanosci. Nanotechnol. 5, 244 (2005)

[54] C. Jayaseelan, A.A. Rahuman, A.V. Kirthi, S. Marimuthu, T. Santhoshkumar, A. Bagavan, K. Gaurav, L. Karthik, K.V. Bhaskara Rao, Spectrochim. Acta A Mol. Biomol. Spectrosc. 90, 78 (2012) 